\title{
THE INTELLECTUAL NATURE OF LAW IN THE CONTEXT OF DIGITAL TRANSFORMATION OF SOCIETY
}

\author{
Alexander A. Bochkov \\ Vitebsk State University named after P.M. Masherov, Vitebsk, Republic of Belarus
}

Introduction: the paper deals with the study of the intellectual aspect of law, its democratic nature in the context of the introduction of innovative technologies in electronic law. The digital transformation of society is based on the "breakthrough" innovations in the economic, political, social and legal spheres. The purpose of the study is to show the influence of mental processes on the origin and change of law. The objectives of the research are to identify the true nature of law, its purpose, the need to create electronic law, to show the opportunities and risks of the digitalization of law, the impact of information technologies on the disclosure of its potential. Methods: a pluralistic methodology that combines universal, general, and specific scientific research methods. The main methods were the dialectical and materialistic, synergetic and transdisciplinary ones. Results: being reasonable in its nature and purpose law is a combination of mathematically precise forms (sources) of law and natural human rights and freedoms, as a condition for the implementation of genuine democracy in a state-civil society. The legal world is a special, abstract, metaphysical reality artificially created by the conventional, creative genius of man. The technology expands the possibilities of the human mind, creating both challenges and risks. Many modern social processes in the conditions of synergetic, nonlinear development, the growth of entropy, disorder, risk, and a massive increase in digital information (BigData), can only be managed and predicted with the help of artificial intelligence (AI). Conclusions: the language of the human brain, neurophysiology, and digital society must be translated into the language of electronic law. To do this, it is necessary to adapt the legal engineering, to digitize the forms (sources) of law, to use the information and communication technologies, the educational platforms in the training of lawyers, to develop the special legislation on the electronic state, electronic government, AI and robotics. The metatheory of digital law, its legislative consolidation, and the mechanism of the law enforcement implementation (including the automatic one) will help to solve this problem.

Key words: consciousness, intelligence, artificial intelligence, digitalization, technology, law.

Citation. Bochkov A.A. The Intellectual Nature of Law in the Context of Digital Transformation of Society. Legal Concept $=$ Pravovaya paradigma, 2021, vol. 20, no. 2, pp. 134-142. (in Russian). DOI: https://doi.org/ 10.15688/lc.jvolsu.2021.2.18

УДК 340.11:159.923.35:004.8

Дата поступления статьи: 16.03.2021

ББК 67.404

Дата принятия статьи: 08.04.2021

\section{ИНТЕЛЛЕКТУАЛЬНАЯ ПРИРОДА ПРАВА В УСЛОВИЯХ ЦИФРОВОЙ ТРАНСФОРМАЦИИ ОБЩЕСТВА}

\author{
Александр Александрович Бочков \\ Витебский государственный университет им. П.М. Машерова, г. Витебск, Республика Беларусь
}

Введение: статья посвящена исследованию интеллектуального аспекта права, его демократической природы в условиях внедрения инновационных технологий в электронное право. Цифровая трансформация общества основывается на «прорывных» инновациях в экономической, политической, социальной и правовой сферах. Цель исследования - показать влияние ментальных процессов на происхождение и изменение права. Задачи исследования: выделить истинную природу права, ее предназначение, необходимость создания электронного права; показать возможности и риски цифровизации права, влияние информационных технологий на раскрытие его потенциала. Методы: плюралистическая методология, объединяющая всеобщие, общие и частнонаучные методы исследования. Основными методами выступали диалектико-материа- 
листический, синергетический и трансдисциплинарный. Результаты: разумное по своей природе, предназначению право - это соединение математически точных форм (источников) права и естественных прав и свобод человека как условие реализации подлинного народовластия в государственно-гражданском обществе. Юридический мир представляет собой искусственно созданную конвенциональным, творческим гением человека особую, абстрактную, метафизическую реальность. Технологии раздвигают возможности человеческого разума, создавая одновременно проблемы и риски. Многими современными общественными процессами в условиях синергетического, нелинейного развития, роста энтропии, беспорядка, риска, шквального увеличения цифровой информации (BigData), управлять, предвидеть результаты наступления последствий можно только с помощью искусственного интеллекта (ИИ). Выводы: язык человеческого мозга, нейрофизиологии, цифрового общества необходимо перевести на язык электронного права. Для этого нужно адаптировать юридическую технику, отцифровать формы (источники) права, задействовать информационно-коммуникационные технологии, образовательные платформы в подготовке юристов, разработать специальное законодательство по электронному государству, электронному правительству, ИИ и робототехнике. Метатеория цифрового права, ее законодательное закрепление, механизм правоприменительной реализации (включая автоматический) помогут решить эту задачу.

Ключевые слова: сознание, интеллект, искусственный интеллект, цифровизация, технологии, право.

Цитирование. Бочков А.А. Интеллектуальная природа права в условиях цифровой трансформации общества // Legal Concept = Правовая парадигма. - 2021. - Т. 20, № 2. - C. 134-142. - DOI: https://doi.org/ 10.15688/lc.jvolsu.2021.2.18

\section{Введение}

Право - это продукт человеческого сознания, гениальная регулятивно-охранительная система, революционно преобразующая мир. Чем выше интеллектуальный, духовно-нравственный уровень общества, тем эффективнее правовая система.

Ввиду своей сложности, многоаспектности и вариативности сознание с трудом поддается изучению и определению. Мозг человека исследован примерно на 1/5.

Немецкий физиолог и философ Э. Дюбуа-Реймон (1818-1896) еще в XIX в. рассматривал его в качестве одной из семи объективно не разгадываемых мировых загадок, проблем, которых мы не знаем и не будем знать: «Idnoramus et ignorabimus». Поэтому для активизации мозга нужно его изучить, реализовать, задействовать «спящие» возможности.

Для создания ИИ необходимо понять структуру, внутренний механизм сознания, его уровни, факторы, влияющие на актуализацию скрытых резервов и способностей. Известный советский и российский нейрофизиолог, академик, научный руководитель Института мозга человека РАН Н.П. Бехтерева (1924-2008) считала, что мы можем говорить о сверхвозможностях мозга, опережающего самого себя и устремленного в будущее. При этом язык нейрофизиологии плохо переводится на языки социологии, воспитания и обучения [2].

Именно сознание явилось определяющей стороной антропосоциогенеза. Учеными окончательно не установлено, что повлияло на происхождение человека: труд, членораздельная речь, языковая коммуникация, развитие интеллекта, «ионизирующая радиация», наступление ледника, сексуальная революция, генная мутация, нарушение инстинктивной программы поведения, духовно-религиозные аспекты, внеземное происхождение [3, с. 10-12].

Нуждается в дополнительном исследовании влияние эволюции ментальных процессов на юридизацию общества, правовой прогресс, персонификацию лица, изменение его правового статуса. Только развитый интеллект в состоянии создать новые средства правового регулирования в быстро меняющемся мире.

Интеллект неразрывно связан с правом, не только как продукт, результат его творчества, деятельности, но и как необходимое условие осуществления, реализации. Вне права цивилизованное человеческое общество обречено на гибель. При этом для функционирования права сознание может играть как созидательную, так и разрушительную роль. Это зависит от правового характера государства, разумности, демократичности, социальности права, интеллектуальности и духовности общества и его членов. 


\section{ТЕОРИЯ И ПРАКТИКА ГОСУДАРСТВЕННО-ПРАВОВОГО РАЗВИТИЯ}

\section{Человеческий интеллект и его формы}

Появление homo sapiens - это результат и продукт длительной биологической, генетической и культурной коэволюции живой природы, форм отражения материи, предсоциальной истории и коммуникации. Человеческий интеллект представляет сплав биологического, психического и общественного, рационального и иррационального, сознательного и бессознательного, включая самосознание, чувства, эмоции и переживания, отражающиеся на вербальном и невербальном уровнях (в языке, речевых сигналах и жестах).

Сознание - это особое идеальное состояние, доступное только человеку, воспринимающему окружающий мир и самого себя. Человек отражает объективную реальность в знаковых формах через призму своей души.

Древние греки подчеркивали интенциональность сознания, активную роль и его направленность на объект. Христианская традиция рассматривала как отблеск, искру Божию, великий дар, связанный с душевными переживаниями, радостью Божьего озарения, самосознания, благодати. В ее границах сознание понималось также как тяжкий крест, наказание за гордыню, дерзость, одержимость постижения греховного посюстороннего и божественного потустороннего мира. Усомнившись в Боге, отказавшись от него, забыв о душе, человек возомнил себя центром Bселенной, что привело к антропоцентризму, индивидуализму и эгоизму. Экономический (инновационный) детерминизм, исходящий из материального расчета, стал определять развитие общества. Практически направленный технизированный разум в условиях капитализации и коммерциализации общественных отношений создал условия для роста материального благосостояния и духовно-нравственной деградации личности.

В сознании человеку даны не только красота окружающей действительности, но и ее оборотная сторона, вызывающая боль, переживания, сострадание, муки совести и приливы раскаяния [19, p. 400].

Диалектико-материалистическая концепция трактовала сознание как свойство высокоорганизованной материи мозга, способное адекватно отражать материальный, объектив- ный мир в его субъективных, идеальных образах. Вместе с тем человека формирует не только окружающий (микро- и макро-) мир, обучение, воспитание, но и он сам - своей активной трудовой деятельностью, самовоспитанием, самосознанием. Неясно, что сыграет определяющую роль. В настоящее время происходит перераспределение воспитательных функций от семьи к школе, учебным заведениям. В условиях перехода к игровым формам обучения клиповое, фрагментарное сознание не зацикливается на сущностных аспектах, теряет в «глубине», убежденности, целостности, системности.

Сознание - представляет собой знание, полученное совместно с другими людьми. Это состояние здравого ума и трезвой памяти, способность отдавать себе отчет в своих чувствах, поступках и руководить ими. Последнее проявляется в юридических категориях вменяемости, дееспособности и деликтоспособности, добросовестности и разумности, равенства и неприкосновенности.

Социальная система может нормально функционировать только при условии воспроизводства такого уровня общественного, группового, индивидуального сознания (включая искусственный интеллект), который по содержанию как минимум адекватен ее запросам, а как максимум - опережает и направляет развитие. Инновационное «прорывное» сознание, связанное с открытиями, творчеством, созиданием, способно изменить не только окружающий мир, но и самого себя.

Современные физикализм, кибернетизм выступают за редуцирование ментальных состояний, выявление автоматизмов мозга, сведение их к физическим процессам. Это позволит моделировать определенные функции мышления через алгоритмы, программы, схемы, воплощающиеся в технических устройствах.

Интеллект (лат. intellectus - познание, понимание, рассудок) - это особая способность мышления, рационального познания, ума, в отличие от душевных составляющих чувств, воли, интуиции, воображения.

Мышление - это высшая форма активного познания субъектом существенных связей объективной действительности, в результате чего он создает новый мир и самого себя. 


\section{Цифровизация права: возможности и риски}

По мнению французского философа, профессора А. Бергсона (1859-1941), интеллект это разумное и рассудочное познание, которое достигает высших форм в методах физико-математических наук. Разлагая целостность на тела и элементы, интеллект конструирует из них искусственные картины мира, но при этом теряет неповторимое и уникальное свойство - «жизненный порыв», основанный на интуиции, - считал мыслитель [17, c. 49]. Право - это проводник и носитель духовно-рациональных начал, государственных норм и естественных прав человека. Государство претендует на то, чтобы его считали «коллективным разумом», а право - «копилкой рациональности и справедливости». Разумное государство и право стремятся к идеальным, истинным, чистым их характеристикам. В настоящее время активно разрабатываются доктрины, внедряющие в практику: умное государство, умное право, умный город, умное регулирование.

Технологии вступают в противоречие с развитием сознания, интеллектуальной и духовной деятельностью человека. Привыкая к автоматизации, человек теряет навыки адекватного мышления, анализа, самостоятельного принятия решения, превращаясь, по сути дела, в биологический придаток машины. Возникает опасность программирования и зомбирования поведения, особенно на массовом уровне. Необходимы фильтры (цензура) информации в сети Интернет, наносящей ущерб гражданским правам и государственному суверенитету. Особенно уязвимой становится частная жизнь граждан (право на анонимность, забвение, «электронную смерть», авторское право на цифровую сущность, право на доступ к информации и ее защите), а также государственные и инновационные секреты. Следует законодательно закрепить возможность использования информации, распространяемой в Интернете, для осуществления юридически значимых действий, что позволит клеветнические (фейковые) данные в сети рассматривать как основание для юридического реагирования.

Еще великий И. Кант в XVII в. сформулировал идею чистого бытия законодатель- ного разума, не принимающего в соображение ни одну из эмпирических целей [7, с. 283]. Он различал метафизические начала в праве как априори заложенную форму и эмпирическую правовую практику. Поэтому право - чистое понятие, направленное на действительность [6, с. 111-112]. Это гармония идей, норм, конструкций, свободных от произвола, субъективизма, невежества, «самое святое, что есть у Бога на Земле».

Г. Кельзен (1881-1973) в работе «Чистая теория права» рассматривал право с содержательной, объективной, внутренней стороны ее собственных закономерностей, с формальнодогматических позиций. Воспринимая норму как мысленное допущение нашего сознания для обеспечения государственного правопорядка, он предлагал освободить ее от идеологических, социологических, философских, психологических оценок и наполнить чисто юридическим содержанием [8, с. 64].

Разумное право по своему предназначению - это право легальное, легитимное, справедливое, соединяющее индивидуальную свободу и коллективную солидарность (В.Д. Зорькин).

Право выступает как синтез свободы и равенства (В.С. Соловьев), где естественные, неотчуждаемые права и свободы человека объективно составляют ценностную основу, исторически обусловленное содержание позитивного права.

Немецкий историк, философ и культуролог О. Шпенглер (1880-1936) считал правовое мышление родственным математическому, поэтому важно установить чистую форму предмета, чистый тип ситуации, чистую связь причины и действия [18, с. 69].

Развитые правовые системы стремятся к математической точности понятий, логической взаимосвязи юридических элементов, духовному, естественно-правовому, разумному наполнению нормы. Не случайно римское частное право именовалось как «писаный разум» (ratio scripta), а сама юридическая деятельность - «разум законов» (ratio legis).

Специфика правовой материи, напрямую зависящей от властных структур государства, его принуждения, гарантий, в том, что форма может становиться определяющей качественной характеристикой содержания (форма государства, форма власти, формы активности 
масс, формы реализации права, формы (источники) права и т. д.). «Legum servi esse debemus, ut liberi esse passimus» («Нужно подчиняться законам, чтобы быть свободным»), «Guod non est in actis, non est in mundo» («Чего нет в документах, того нет и на свете»), - говорили древние римские юристы. Поэтому форма права становится обязательным юридически узаконенным состоянием государственно-правовой материи.

Норма, где четко выделены элементы юридической структуры, поддается цифровизации. Трудно (невозможно) отцифровать нормы-дефиниции, нормы-декларации, нормыопределения, нормы-принципы. Существует противоречие между математически строгим выражением нормы и ее духовным, мировоззренческим наполнением.

Диалектическая взаимозависимость формы и содержания имеет свою специфику на юридическом уровне, составляя глубину и тайну, единство и противоречие должного и возможного поведения. Здесь правовая конвергенция, по мнению профессора С.С. Алексеева, представляет собой органическое единство «чистых» правовых форм с соблюдением и реализацией на практике прав человека $[1$, c. 144]. Такое единство возможно в правовом гражданском государстве, объединяющем государство и гражданское общество.

По словам И. Канта, «чисто эмпирическое учение о праве - это голова (подобная деревянной голове в басне Федра), которая может быть прекрасна, но, увы, не имеет мозга» [6, с. 139].

Талантливый советский ученый, доктор философских наук, профессор, специалист в области сознания М.К. Мамардашвили (19301990) считал, что истинное право не содержит в себе «оснований зла и несчастья» $[10$, c. 93]. Не случайно именно с правом и религией связывают земную надежду на царство разума, справедливости, торжество правды, истины, совести и процветания.

\section{Юридический мир как особая абстрактная и конкретная реальность}

Юридический мир, по словам дореволюционного российского правоведа, профессора, доктора римского права И.А. Покровского
(1868-1920), это особая реальность. Физический человек, превращаясь в юридический субъект права, в значительной степени утрачивает свою естественную сущность, физиологические и психические качества. Для субъекта права безразличен пол, рост, цвет волос человека и т. д. [12, с. 147]. Этому также способствует виртуальный, искусственный мир со своим языком и законами, дополняющий и изменяющий объективную реальность.

Российский и украинский юрист, философ и социолог Б.А. Кистяковский (1868-1920) считал, что правовая действительность находится между произведениями скульптуры и живописи, с одной стороны, и произведениями литературы и музыки - с другой, причем она ближе к первой [9, с. 336]. В зарубежных странах существуют примеры наделения юридическим статусом субъекта права Матери-Земли (Пачамамы), реки, священных текстов сикхов, орангутангов [13, с. $18 ; 15$, с. 6-7].

Юридический мир представляет собой искусственно созданную конвенциональным, творческим гением человека особую, абстрактную, метафизическую реальность - понятий, догм, доктрин, фикций, презумпций, техник, субъектов, объектов, - надстраиваемую над эмпирической действительностью с целью сохранения, развития и совершенствования ее. Это - узаконенная форма социального бытия, опирающаяся на такие системообразующие конструкции, как: государство, право, юридическая ответственность, правопреемство, воля, договор, физическое лицо, юридическое лицо. Два последних играют роль субъектов права [4, с. 17-23].

По мнению И. Канта, лицом может быть только тот субъект, которому могут быть вменены его поступки. Вещь - это предмет (Ding), которому ничто не может быть вменено [6, с. 132]. Если дореволюционные российские правоведы Е.Н. Трубецкой, Г.Ф. Шершеневич считали, что лицо - это исключительно юридическое понятие, а юридический субъект - невидим и неосязаем, то австрийский нормативист Г. Кельзен полагал, что человек становится лицом при помощи юридической конструкции, нормативного, искусственно созданного понятия [4, с. 23].

Современные био- и нанотехнологии позволяют в значительной степени изменить 
природные данные человека, что оказывает влияние на его персонификацию и правовой статус. И даже биологическое сознание, которое в течение длительного времени считали единственным отличительным признаком личности, также поддается массированному информационному, психологическому, телепатическому воздействию, манипулированию, зомбированию и даже перепрограммированию.

При этом, если через юридическую «маску» осуществляется удвоение человека, личности, превращение в лицо, персону, то через электронную, цифровизацию - утроение, появление электронного лица, квазиюридического лица, виртуальных правоотношений. Это происходит путем наделения субъектов права электронными правами и обязанностями: право на виртуальную личность, на безопасное использование сети Интернет, право на цифровой профиль, на электронную сделку, электронную подпись, электронное обращение, защиту от несанкционированного воздействия ИИ и роботов и т. д.

Возможно противоречие между открытостью и закрытостью информации, публичностью и электронным забвением. Существует опасность установления в государстве тотального цифрового контроля и использования цифровых технологий в корыстных целях $[16$, с. 52].

Юридизация и цифровизация общественных отношений предполагают и дополняют друг друга. Однако форма не должна подменять содержание. Если структуру, форму можно облечь в цифровую, электронную оболочку с использованием искусственного интеллекта, то содержание требует максимального включения человека, его рациональных и духовных свойств.

Информационные технологии помогают рассчитать прогнозные показатели эффективности принятия НПА, их психологическое восприятие населением, что предохраняет от необдуманных социальных, политических, экономических и правовых решений. Технологии оптимизируют работу государственного аппарата, делают ее более прозрачной и подконтрольной гражданскому обществу, позволяют активнее бороться с бюрократией и коррупцией, способствуют качественному подбору кадров [11, с. 133].
В настоящее время в Республике Беларусь в рамках конституционной реформы обсуждаются вопросы изменения конституционного, уголовного, административного, гражданского, семейного, налогового, корпоративного, процессуального права. Рассматриваются проблемы передачи части властных полномочий от Президента - Правительству, Парламенту, органам местного управления и самоуправления, а также совершенствования работы государственных органов, применения законодательства, развития предпринимательской деятельности, повышения качества оказания юридических услуг. Для выработки взвешенных предложений привлечены представители депутатского корпуса, государственного аппарата, научных кругов, бизнеса, гражданского общества.

Белорусские граждане активно участвуют в нормотворческом процессе путем публичного обсуждения проектов правовых актов. В соответствии со ст. 7 Закона Республики Беларусь «О нормативных правовых актах» от 17 июля 2018 г. № 130-3 официальной площадкой для публичного обсуждения проектов нормативных правовых актов является сайт «Правовой форум Беларуси». Например, на конец марта 2021 г. только в электронной форме внесено от граждан и организаций 7157 предложений по изменению Конституции Республики Беларусь и законодательных актов [14]. Вместе с тем отсутствует правовой механизм анализа, обобщения, отбора и внесения предложений в Конституционную комиссию. Необходимо законодательно закрепить положение о Конституционной комиссии, ее полномочиях, составе и функциях.

\section{Результаты}

Интеллектуально-духовно-нравственный потенциал права становится особенно востребованным в условиях информационно-цифровой революции, применения ИИ и робототехники. Информационные технологии через электронное голосование, электронное обсуждение, электронную демократию, электронное государство позволят оптимизировать работу государственного аппарата, более полно задействовать потенциал гражданского общества. Это требует изменения правовой систе- 
мы, ее институтов на доктринальном, законодательном и правоприменительном уровнях, что позволит включить скрытые резервы для оперативного, гибкого реагирования на вызовы времени [5, с. 301-303].

\section{Заключение}

Социальную и демократическую природу права можно реализовать только в условиях консолидированного общества с возрожденными национальными ценностями, прозрачной системой выборов, сильным гражданским обществом. Речь идет о коллаборативном технологическом управлении. Здесь нужны такие технологии, которые могут просчитать, моделировать результаты принимаемых политических, социальных и правовых решений, смягчать негативные последствия.

Применение информационно-коммуникационных технологий позволит поставить многие процессы правотворчества и правоприменения на автоматизированную основу, своевременно выявлять сбои и неполадки правового механизма и включать систему самонастройки и саморегулирования.

В условиях цифровой трансформации общества только инновационные «прорывные» технологии в экономике, управлении, социальной и правовой сферах способны превратить Республику Беларусь и Российскую Федерацию из догоняющих в лидирующие страны. Это основа обеспечения национального суверенитета, конкурентноспособности и процветания государства, прав и свобод граждан.

\section{СПИСОК ЛИТЕРАТУРЫ}

1. Алексеев, С. С. Тайна права. Его понимание, назначение, социальная ценность / С. С. Алексеев. - М. : Норма, 2001. - 161 с.

2. Бехтерева, Н. П. Мозг человека - сверхвозможности и запреты / Н. П. Бехтерева. -Электрон. текстовые дан. - Режим доступа: https://www.nkj.ru/ archive/articles/6406/ (дата обращения: 13.03.2021). Загл. с экрана.

3. Бочков, А. А. Философские проблемы антропосоциогенеза / А. А. Бочков // Социальная философия : учеб. пособие / А. А. Бочков, Э. И. Рудковский ; под ред. Э. И. Рудковского. - Витебск : Изд-во ВГУ им. П.М. Машерова, 1999. - С. 10-12.
4. Гаджиев, Г. А. Является ли робот - агент лицом? / Г. А. Гаджиев // Журнал российского права. - 2018. - № 1. - С. 15-29.

5. Демичев, Д. М. Общая теория права : учеб. пособие / Д. М. Демичев, А. А. Бочков. - Минск : Вышэйшая школа, 2019. - 480 с.

6. Кант, И. Метафизика нравов. В 2 ч. Ч. 1. Метафизические начала учения о праве / И. Кант // Сочинения : в 6 т. / [под общ. ред. В. Ф. Асмуса, А. В. Гулыги, Т. И. Ойзермана]. - М. : Мысль, 19631966. - Т. 4, ч. 2. -478 с.

7. Кант, И. Сочинения на немецком и русском языках / И. Кант. - М., 1994. - Т. 1.-586 с.

8. Кельзен, Г. Чистое учение о праве : сб. переводов / Г. Кельзен. - Вып. 1. - М., 1987. - 195 с.

9. Кистяковский, Б. А. Социальные науки и право. Очерки по методологии социальных наук и общей теории права / Б. А. Кистяковский. - М., 1916. $-704 \mathrm{c}$.

10. Мамардашвили, М. Кантовские вариации /М. Мамардашвили. - М., 1997. - 320 с.

11. Матыцин, Д. Е. Обеспечение исполнения государственных и муниципальных контрактов: банковские гарантии и цифровые технологии / Д. Е. Матыцин, И. В. Балтутите // Евразийский юридический журнал. - 2020. - № 11 (150). - С. 133-136.

12. Покровский, И. А. Основные проблемы гражданского права / И. А. Покровский. - М., 1998. $-234 \mathrm{c}$.

13. Попова, А. В. Новые субъекты информационного общества: к вопросу о нормативном правовом регулировании /А. В. Попова // Журнал российского права. - 2018. - № 11. - С. 14-24.

14. Правовой форум Беларуси. - Электрон. текстовые дан. - Режим доступа: https://forumpravo.by/ (дата обращения: 13.03.2021). - Загл. с экрана.

15. Робот и человек: новое партнерство? / Ю. А. Тихомиров, Н. Б. Крысенкова, С. А. Нанба, Ж. А. Маргушева // Журнал зарубежного законодательства и сравнительного правоведения. -2018. № 5. - C. 5-10

16. Талапина, Э. В. Права человека в интернете / Э. В. Талапина // Журнал российского права. 2019. - № 2 (266). - С. 41-54.

17. Философский энциклопедический словарь / гл. ред. : Л. Ф. Ильичев и др. - М. : Сов. Энцикл., 1983. $-840 \mathrm{c}$.

18. Шпенглер, О. Закат Европы. Очерки морфологии мировой истории / О. Шпенглер. - Т. 2. M., 1998. - 606 c.

19. Chegovadze, L.A. Civil Legal Relationship as a Means of Realization of Interests on the Internet / L. A. Chegovadze, E. I. Inshakova, A. O. Inshakova // Competitive Russia: Foresight Model of Economic and Legal Development in the Digital Age: Proceedings of the International Scientific Conference 
in Memory of Oleg Inshakov (1952-2018) / Editors A. O. Inshakova, E. I. Inshakova. - Cham : Springer Nature, 2020. - P. 400-406.

\section{REFERENCES}

1. Alekseev S.S. Tajna prava. Ego ponimanie, naznachenie, social'naya cennost' [The Secret of Law. Its Understanding, Purpose, and Social Value]. Moscow, Norma Publ., 2001. 161 p.

2. Bekhtereva N.P. Mozg cheloveka sverhvozmozhnost $i$ izaprety [The Human Brain Superpowers and Prohibitions]. URL: https://www.nkj. ru/archive/articles/6406 (accessed 13 March 2021).

3. Bochkov A.A. Filosofskie problemy antroposociogeneza [Philosophical Problems of Athroposociogenesis]. Bochkov A.A., E.I. Rudkovskij. Socialnaja filosofija: uchebnoe posobie. Vitebsk, VSU named after P.M. Masherov, 1999, pp. 10-12.

4. Gadzhiev G.A. Yavlyaetsya li robot agent licom? [Is a Robot an Agent Person?]. Zhurnal rossijskogo prava [Journal of Russian Law], 2018, no. 1, pp. 15-29.

5. Demichev D.M. Obshchaya teoriya prava: uchebnoe posobie [General Theory of Law: A Textbook]. Minsk, Vyshejshaya shkola, 2019.480 p.

6. Kant I. Metafizika nravov. V 2 chastyah. Chast' 1. Metafizicheskie nachala ucheniya o prave [Metaphysics of Morals. In 2 parts. Part 1. Metaphysical Principles of the Doctrine of Law]. Sochinenija: $v 6$ tomah [Essays in six volumes]. Vol. 4, ch. 2. Moscow, Mysl Publ. 478 p.

7. Kant I. Sochineniya na nemeckom i russkom yazykah [Works in German and Russian], vol. 1. Moscow, 1994. 586 p.

8. Kel'zen G. Chistoe uchenie o prave: sbornik perevodov [Pure Doctrine of Law: Collection of Translations]. Iss. 1. Moscov, 1987. 195 p.

9. Kistyakovskij B.A. Social'nye nauki i pravo. Ocherki po metodologii social'nyh nauk i obshchej teorii prava [Social Sciences and Law. Essays on the Methodology of the Social Sciences and the General Theory of Law]. Moscow, 1916. 704 p.

10. Mamardashvili M. Kantovskie variacii [Kantian Variations]. Moscow, 1997.320 p.
11. Matycin D.E., Baltutite I.V. Obespechenie ispolneniya gosudarstvennyh i municipal'nyh kontraktov: bankovskie garantii i cifrovye tekhnologii [Ensuring the Execution of State and Municipal Contracts: Bank Guarantees and Digital Technologies]. Evrazijskij yuridicheskij zhurnal [Eurasian Legal Journal], 2020, no. 11 (150), pp. 133-136.

12. Pokrovskij I.A. Osnovnye problemy grazhdanskogo prava [The Main Problems of Civil Law]. Moscow, 1998. 234 p.

13. Popova A.V. Novye sub'ekty informacionnogo obshchestva: $\mathrm{k}$ voprosu o normativnom pravovom regulirovanii [New Subjects of the Information Society: On the Issue of Normative Legal Regulation]. Zhurnal rossijskogo prava [Journal of Russian Law], 2018, no. 11, pp. 14-24.

14. Pravovoj forum Belarusi [Legal Forum of Belarus]. URL: https://forumpravo.by/ (accessed 13 March 2021).

15. Tihomirov Yu.A., Krysenkova N.B., Nanba S.B., Margusheva Zh.A. Robot i chelovek: novoe partnerstvo? [Robot and Human: A New Partnership?]. Zhurnal zarubezhnogo zakonodatel'stva $i$ sravnitel'nogo pravovedeniya [Journal of Foreign Legislation and Comparative Law], 2018, no 5, pp. 5-10.

16. Talapina E.V. Prava cheloveka v internete [Human Rights on the Internet]. Zhurnal rossijskogo prava [Journal of Russian Law], 2019, no. 2 (266), pp. 41-54.

17. Ilyichev L.F. et al., eds. Filosofskij enciklopedicheskij slovar' [Philosophical Encyclopedia]. Moccow, Sov. Encyclopedia Publ., 1983.840 p.

18. Shpengler O. Zakat Evropy. Ocherki morfologii mirovoj istorii [The Decline of Europe. Essays on the Morphology of World History]. Vol. 2. Moscow, 1998. 606 p.

19. Chegovadze L.A., Inshakova E.I., Inshakova A.O. Civil Legal Relationship as a Means of Realization of Interests on the Internet. A.O. Inshakova, E.I. Inshakova, eds. Competitive Russia: Foresight Model of Economic and Legal Development in the Digital Age: Proceedings of the International Scientific Conference in Memory of Oleg Inshakov (1952-2018). Cham, Springer Nature Publ., 2020, pp. 400-406. 


\section{ТЕОРИЯ И ПРАКТИКА ГОСУДАРСТВЕННО-ПРАВОВОГО РАЗВИТИЯ}

\section{Information About the Author}

Alexander A. Bochkov, Candidate of Sciences (Philosophy), Associate Professor, Dean of the Faculty of Law, Vitebsk State University named after P.M. Masherov, Prosp. Moskovskiy, 33, 210038 Vitebsk, Republic of Belarus, vsu@vsu.by, https://orcid.org/0000-0001-5634-3318

\section{Информация об авторе}

Александр Александрович Бочков, кандидат философских наук, доцент, декан юридического факультета, Витебский государственный университет им. П.М. Машерова, просп. Московский, 33, 210038 г. Витебск, Республика Беларусь, vsu@vsu.by, https://orcid.org/0000-0001-5634-3318 